\title{
Habitação de Interesse Social: Cidades transformadas pela inclusão dos sujeitos sociais e a experiência no semiárido
}

\author{
Sônia Regina Tavares Barreto ${ }^{1}$; Fernando Augusto Kursancew ${ }^{2}$
}

\begin{abstract}
Resumo: Este artigo apresenta o trabalho de interesse social no território urbano, com enfoque na política de assentamento com famílias de baixa renda; considerando nesse processo o fortalecimento do planejamento democrático das cidades no acesso à moradia digna e exercício da cidadania, dessa forma, permitindo a ampliação do conceito de moradia numa dimensão mais ampla, não se limitando apenas a construção de casas, mas a partir de ações de interesse social que consistam em garantia de espaços de participação popular e porta de entrada para benefícios e direitos, tais como: saúde, saneamento, educação, transporte público, meio ambiente, trabalho e renda, entre outros. Neste cenário urge compreender a importância do surgimento do Ministério das Cidades na PNH Política Nacional de Habitação com a consolidação do Trabalho Social como parte obrigatória nos programas de habitação. Trará a luz um Brasil que durante décadas amargou uma grande dívida social com a sua população, e frente a isso, vê-se a necessidade de entender como a exclusão contribui para tornar as diferenças socioeconômicas ainda mais profundas, e como providencialmente as políticas públicas de habitação, por meio da reforma urbana, estão mudando o cenário das cidades. Com efeito, este artigo parte de uma revisão bibliográfica para se chegar a um estudo indutivo.
\end{abstract}

Palavras-chave: exclusão espacial; desenvolvimento urbano; trabalho social; inclusão social; desenvolvimento sustentável.

\section{Social Interest Housing: Cities transformed by the inclusion of social subjects and the experience in the semi-arid}

\begin{abstract}
This article presents the work of social interest in the urban territory, focusing on the policy of settlement with low income families; considering in this process the strengthening of the democratic planning of cities in the access to decent housing and exercise of citizenship, in this way, allowing the widening of the concept of housing in a broader dimension, not limited to the construction of houses, but from actions of social interest that consists of guaranteeing spaces of popular participation and a gateway to benefits and rights, such as health, sanitation, education, public transportation, environment, work and income, among others. In this scenario it is imperative to understand the importance of the emergence of the Ministry of Cities in the PNH - National Housing Policy with the consolidation of Social Work as a mandatory part of housing programs. It will bring to light a Brazil that for decades has embittered a great social debt with its population, and in front of this, it is necessary to understand how the exclusion contributes to make the socioeconomic differences even more profound, and as providentially the public policies of housing, through urban reform, are changing the landscape of cities. In fact, this article starts from a bibliographical review to arrive at an inductive study.
\end{abstract}

Keywords: spatial exclusion; urban Development; social work; social inclusion; sustainable development.

\footnotetext{
${ }^{1}$ Assistente Social, discente do Programa de Pós-Graduação em Administração Pública da Universidade Federal do Vale do São Francisco. Contato: soniareginatavares@bol.com.br;

${ }^{2}$ Arquiteto e Urbanista, Professor orientador do Programa de Pós-Graduação em Administração Pública da Universidade Federal do Vale do São Francisco. Contato: fernando.augusto@univasf.edu.br.
} 


\section{Introdução}

Esse artigo identifica a importância do trabalho de interesse social na implementação do processo de pós-ocupação do Programa Minha Casa Minha Vida com famílias de baixa renda, a partir do olhar dos sujeitos sociais acerca do que venha a ser moradia. Para tanto, faz um retrospecto do processo de exclusão espacial por vulnerabilidades, a fim de que se questione a emergente tarefa de transformar as cidades a partir do provimento de moradias com acesso a condições básicas necessárias, tais quais: fornecimento de água tratada, coleta de lixo, serviço de esgoto, atentando para o que propõe a Organização das Nações Unidas, ONU, em sua conceituação de sustentabilidade. Discorre, ainda, sobre o fenômeno "crescimento demográfico das cidades", que gerou quadros de desigualdades e desenvolvimento urbano desordenado, com espaços limitados e concentração de pessoas em localidades com infraestruturas precárias; no Brasil em particular, em face do êxodo rural $^{1}$ e processo de industrialização ${ }^{2}$, que foram grandes impulsionadores da aceleração da urbanização no país, intensificada a partir do século XX.

A partir Constituição Federal de 1988 o direito a moradia se torna parte importante na política urbana, surgindo à necessidade de ampliação do seu conceito, sendo imprescindível discorrer sobre o a criação do Estatuto das Cidades em 2001, que veio para regulamentar os art. 182 e 183 da política de habitação; como também a importância da criação do Ministério das Cidades no ano de 2003 que tem em suas prerrogativas a elaboração de políticas públicas de desenvolvimento urbano, de habitação e saneamento básico que juntamente com Conselho das Cidades, criado em 2004, tem a função de ampliar a participação popular.

E para fundamentar a obrigatoriedade do desenvolvimento do trabalho social no Programa Nacional de Habitação de Interesse Social foi abordada a criação da Lei n ${ }^{\circ}$ 11.124/05, que dispõe sobre o SNHIS - Sistema Nacional de Habitação de Interesse Social, e institui o FNHIS - Fundo Nacional de Habitação de Interesse Social gerido por um Conselho Gestor. Sendo também parte importante de todo esse processo o PAC - Programa de Aceleração de Crescimento, lançado em 2007, que promoveu a retomada do planejamento e execução de grandes obras de infraestrutura social, urbana; e por fim, o PMCMV que vem sendo

${ }^{1}$ Fenômeno social que se refere ao processo de migração da população rural para os centros urbanos.

1014

Id on Line Rev. Mult. Psic. V.12, N. 40., 2018 - ISSN 1981-1179

Edição eletrônica em http://idonline.emnuvens.com.br/id 
implementadas desde o ano de 2009, objetivando promover às famílias de baixa renda o acesso à moradia digna por meio de cooperativas habitacionais, associações e demais entidades privadas sem fins lucrativos. Essa nova ordem inaugura uma política descentralizada com a participação popular no controle social como fator de influência.

Como eixo principal, esse estudo aborda as principais diretrizes do Trabalho de Interesse Social com famílias de baixa renda no PMCMV, e como instrumento de aferição do processo de assentamento, será analisada a ocupação pós-obra que ocorreu no município de Juazeiro $^{3}$, estado da Bahia, no residencial Brisa da Serra, realizando assim um parâmetro entre os processos de exclusão e as metodologias do trabalho social que confere aos sujeitos sociais a ressignificação do termo moradia em uma dimensão que vai além de construção de casas. Nesse processo foi importante discorrer de que formas o ambiente construído adapta-se às novas condições, interpretando a função da cidade a partir do princípio de desenvolvimento sustentável. Ao final desse estudo foi possível avaliar não só a satisfação dos moradores como também a sua percepção do que venha a ser o termo moradia.

\section{Metodologia}

Esse artigo foi guiado por uma revisão bibliográfica dos principais contextos de construção do PNH no Brasil e do processo de exclusão espacial, tendo como eixo principal um estudo de caso no assentamento da comunidade do Residencial Brisa da Serra, localizado na cidade Juazeiro-BA, região semiárida do nordeste. Tal estudo se deu por análise de pesquisa por método indutivo, no qual o conhecimento se forma por meio de experiência vivenciada e de comprovações particulares e coletivas no elo entre profissionais e moradores, com a finalidade de abordar a habitação de interesse social, o conceito de moradia e como os sujeitos sociais definem a função da cidade.

\footnotetext{
${ }^{3}$ A cidade de Juazeiro tem sua localização ao norte do Estado da Bahia, na microrregião do Submédio do vale do São Francisco, com um territorial de $6.390 \mathrm{~km}^{2}$ de extensão. Situada na margem direita do rio São Francisco, apresenta uma população de 197.965 habitantes (Dados do IBGE, 2010). Disponível em: https://www6.juazeiro.ba.gov.br/cidade/. Acessado em 25 de set. 2017.
} 
O levantamento bibliográfico foi feito nas bases de dados: Scielo, Google Acadêmico, Medline e Portal Capes. Foram utilizados artigos e periódicos. As palavras-chave utilizadas foram: exclusão espacial; desenvolvimento urbano; trabalho social; inclusão social; desenvolvimento sustentável. Para coleta de dados, utilizou-se uma estratégia no processo de revisão para identificar e omitir estudos não relevantes, através de requisitos como qualidade e fontes reconhecidamente confiáveis.

\section{Resultados e Discussão}

Os achados bibliográficos revelam que discutir sobre justiça social pela busca de novos conceitos de moradia e valores sociais implica no repensar das trajetórias culturais, jurídicas e sociais estabelecidas ao longo da história brasileira [...] a projeção da força de sujeitos sociais como fonte de legitimação do lócus sociopolítico e da constituição emergente de direitos que se pautam pela dignidade humana [...] (WOLKMER, 2000, p. 142). Neste contexto, a articulação que norteia o direito a cidade para sua aplicação concreta e real pode exercer um papel educativo, que provoque o exercício da cidadania, da democracia e das necessidades transformadoras da sociedade como também políticas.

\section{Habitação e Segregação: apontamentos sobre a Reforma Urbana no Brasil}

A Constituição Brasileira aponta que moradia é um direito social exigível em face à ação do Estado por meio da execução de políticas públicas habitacionais. Sendo também dever do Estado adotar medidas de promoção e proteção para que não haja impedimento ao acesso deste direito. As convenções e tratados a nível internacionais têm natureza vinculadora aos países signatários ${ }^{4}$, acarretando responsabilidades aos Estados pela falta de cumprimento das obrigações assumidas (OSÓRIO, 2003, p.19).

De acordo com o IBGE - Instituto Brasileiro de Geografia e Estatística, em sua publicação Números em Brasil (2013, p. 80).

${ }^{4}$ Refere-se aos países que subscreve contrato, carta ou outro documento e que entra em acordo com o conteúdo apresentado. 
O desafio urbano está em ajustar o compasso da urbanização com o do acesso à moradia e ao saneamento, tendo em vista, por exemplo, que o ritmo de urbanização brasileira é mais acelerado que os vagarosos passos dados em relação às melhorias de infraestruturas de saneamento. Este desafio revela que o aumento dos índices ao acesso aos domicílios particulares permanentes não garante o direito à moradia plena, entendida como moradia infraestruturada [...] (IBGE 2013, p. 80).

As cidades cresceram em um ritmo acelerado, em contrapartida a esse processo, se apresenta um quadro de exclusão por desigualdades socioeconômicas, tendo como agravantes um sistema que alimenta a má distribuição de riquezas, problemas de planejamento e má gestão urbana; e nesse contexto se apresentam políticas públicas ineficazes e distantes de seu verdadeiro papel [...] que excluem em vez de incluir, desintegram em vez de integrar, dificultam em vez de facilitar, em especial quando se trata de atender as demandas das classes sociais mais baixas (FERREIRA, W e UEMURA, 2008, p.6, apud PAZ E TABOADA, 2010).

Esse mapa evidencia não só uma dívida social para com a população de baixa renda, como também a necessidade de políticas públicas que contemplem efetivamente tais demandas. Uma emergente Reforma Urbana teria que trazer em suas prerrogativas a função de tornar as cidades em ambientes habitáveis, com infraestrutura e qualidade de vida para a população, principalmente os mais empobrecidos. [...] que tivesse como centralidade o direito à moradia, e que se relacionasse com outros temas como transporte público e acesso ao trabalho. (BONDUKI, 2009, p. 177, apud CAFRUNE, 2016, p 187).

Bonduki (1994, p. 724) destaca que, historicamente a origem de produção de habitação social pelo Estado teve seu início em larga escala, no século XX, em 1937, [...] dos Institutos de Aposentadoria e Pensões (IAPs) ${ }^{5}$ e das Carteiras Prediais ${ }^{6}$, que foram iniciadas pela instituição da Fundação da Casa Popular ${ }^{7}$, ações relevantes no sentido da criação de habitação de interesse social orquestradas pelos governos populistas, sinalizando dessa forma, o processo de transformações que as cidades teriam que passar para modificar as normas estabelecidas pela exclusão de espaços urbanos, que de forma incisiva desfavorecia as classes menos favorecidas socioeconomicamente.

No ano de 1963, com as mobilizações de diversas frentes, sendo todas essas ações impulsionadas pelo Instituto dos Arquitetos do Brasil, a proposta de uma reforma urbana é

\footnotetext{
${ }^{5}$ Em conjunto com a Caixa Econômica Federal, disponibilizava crédito imobiliário para financiamento de imóveis.

${ }^{6}$ Criadas com a finalidade de permitir o financiamento imobiliário com taxas de jurus bem reduzidas, com prazos maiores para pagamento.

${ }^{7}$ Órgão da Política Habitacional que atendia a oferta de financiamento para a aquisição ou construção da casa própria,
} 
formulada no Congresso Nacional; e em 1964 com o chamado Golpe Militar, o Brasil passa a vivenciar um regime ditatório (estendido até o ano de 1984), prorrogando assim a efetivação das reformas necessárias na política urbana. (JÚNIOR E UZZO, 2009, p.259). Em 1986, o Movimento Reformista conceitua habitabilidade em um novo patamar ético social, que desaprova as cidades como fonte lucrativa de uma minoria em detrimento da pobreza de grande parte da população. Surge ai, portanto, a denúncia do quadro das desigualdades social, refletindo a dualidade vivida em uma mesma cidade: a cidade dos ricos e a cidade dos pobres, a cidade legal e a cidade ilegal; tal situação não cabe mais no contexto reformista.

Um dos articuladores importante do Plenário em pró da participação da sociedade no processo de criação da Constituição Federal foi o arquiteto Francisco Whitaker, no ano de 1987. O Fórum criado na ocasião garantiu a participação e voz da população na nova Carta Magna, abrindo o devido espaço para a democracia participativa pós-regime ditatorial, e nesse contexto foi iniciada a formulação da Emenda pela Reforma Urbanista.

[...] proposta que colocou na agenda da constituinte o tema da Política Urbana (esta seção, com os artigos 182 e 183, não existia no projeto de Constituição elaborado originalmente), dando origem ao Estatuto da Cidade, instrumento essencial para todo o processo de planejamento urbano participativo que vem sendo implementado no Brasil e que apenas foi aprovado em 2001. (BONDUKI, 2009, p. 177).

A construção da Constituição Federal foi um período de grande participação popular que permitiu a formação de grupos heterogêneos, que dentro desse cenário atuavam em diversos segmentos sociais e em diferentes e complementares campos urbanísticos, todos articulados com diferentes esferas da sociedade civil organizada, movimentos e grupos, entidades de profissionais e categorias sindicais; entre elas se encontravam a Federação Nacional dos Engenheiros, Federação Nacional dos Arquitetos, Federação de Órgãos para Assistência Social e Educacional, Articulação Nacional do Solo Urbano, Associação dos Mutuários, Movimento dos Favelados, Federação das Associações dos Moradores do Rio de Janeiro, Pastorais, movimentos sociais de luta pela moradia, entre outros grupos; todos em prol de mudanças que viesse a ampliar os artigos constitucionais 182 e 183.

Essas entidades assumiram a tarefa de elaborar uma proposta de lei a ser incorporada na Constituição Federal, com o objetivo de modificar o perfil excludente das cidades brasileiras, marcadas pela precariedade das políticas públicas de saneamento, habitação, transporte e ocupação do solo urbano, assim configurado pela omissão e descaso dos poderes públicos. (JÚNIOR \& UZZO, 2009, p. 260) 
Essas percepções diferenciadas permitiram contribuições e troca de experiências entre as entidades, sendo formulada uma proposta, produto de lutas e participação popular que garantisse cidades mais justas no enfrentamento as desigualdades dos espaços urbanos a partir da construção de políticas públicas. Dessa maneira, essa nova ordem ética sobre a cidade, politiza um discurso e uma plataforma política dos movimentos de lutas sociais urbanas, em que o acesso à cidade com cidadania é um direito a todos os seus moradores e não de um grupo restrito. $\mathrm{O}$ direito à cidade que se cumpre pela gestão democrática e controle social da população, distinguindo assim a função social da cidade, pela garantia da justiça social e de garantia de condições de acesso digno a cidade, sem espaços privilegiados apenas a terminadas camadas sociais em acessão.

Com isso, inaugura no país um projeto que reivindicava uma nova cidade e propunha
a quebra dos privilégios de acesso aos espaços das cidades. Configura-se uma
politização que vai além da questão urbana porque se estende para o âmbito da justiça
social e da igualdade. Tem como centro nodal a questão da participação democrática
na gestão das cidades, tão discriminada pela lógica excludente dos planos
tecnocráticos dos anos 1960 e 1970, apoiados apenas em saberes técnicos, dos quais
a população era considerada incapaz de saber, agir e decidir. (JÚNIOR \& UZZO,
2009, p. 261)

Nesse sentido, os artigos 182 e 183 da Constituição Federal vêm definir o parágrafo da política de desenvolvimento urbano, ainda que de forma não tão abrangente tal qual urge o processo de Reforma Urbana. Vale salientar no parágrafo $4^{\circ}$, inciso II, o imposto sobre a propriedade predial e territorial urbana como garantidor da função social da propriedade, que nesse caso a progressividade a que se refere o imposto previsto no inciso relaciona-se a ideia de que o município garante políticas públicas de desenvolvimento urbano, e que é por meio dessa arrecadação que irá cumprir a função social da propriedade. O objetivo do IPTU deve ser observado e cumprido por aqueles que possuem propriedades, e assim permitir que todos usufruam o bem estar que a cidade tem o dever de proporcionar.

Com todas essas mudanças, os movimentos articulados deram vez à criação do Fórum Nacional de Reforma Urbana, pressionando a tão almejada regulamentação do Capítulo da política urbana, e apesar da pressão constante do Fórum de Reforma Urbana, a regulamentação dos capítulos 182 e 183 da Constituição Federal foram aprovadas no Congresso Nacional apenas 13 anos depois, com a criação da lei nº 10.257 no ano de 2001 que finalmente estabelece o Estatuto da Cidade, ampliando o espaço da política pública urbana e estabelecendo normas de ordem pública e de interesse social. A nova ordem não só regula o uso da propriedade urbana 
em prol da coletividade, como também do equilíbrio socioambiental (Brasil, 2001, p. 17). O Estatuto compõe diretrizes gerais da política urbana, com a finalidade de combater as desigualdades e permitir acesso à cidade com cidadania.

Outro ganho importante no processo da Reforma Urbana foi à criação do Ministério das Cidades no ano de 2003, ampliando o marco regulatório da PNH. O ministério das Cidades tem como principal missão transformando as cidades em espaços mais humanizados, ampliando o acesso da população à moradia, incluindo temas como saneamento e transporte.

Para Maricato (2006), o Ministério das Cidades estruturou-se a partir dos três principais problemas sociais que mais afligem as questões urbanísticas, e que estão intimamente relacionados ao território, são eles: [...] a moradia, o saneamento ambiental (que agrega água, esgoto, drenagem e coleta e destinação de resíduos sólidos) e as questões reunidas sob o tema do transporte da população urbana - mobilidade e trânsito. (MARICATO, E. 2006, p. 215)

Outra questão bastante importante na pauta da ocupação do solo se localiza no art. $4^{\circ}$ do Estatuto das Cidades, que define as condições para uso dos solos urbanos a partir das Zonas Especiais de Interesse Social, mais conhecida como ZEIS. Tais zonas geram bastante discursões por conta das relações entre ocupação de solo versus especulações imobiliárias; e é nesse contexto que a gentrificação ${ }^{8}$ aparece como um processo de investimentos altos a fim de atender ao interesse da iniciativa privada; ou seja, a cidade mesmo sendo de interesse público, pode tender a ser planejada em favorecimento dos chamados especuladores, contrapondo as prerrogativas que amplia o acesso equitativo da cidade para todos.

São áreas demarcadas no território de uma cidade, para assentamentos habitacionais
de população de baixa renda. Devem estar previstas no Plano Diretor e demarcadas
na Lei de Zoneamento. Podem ser áreas já ocupadas por assentamentos precários, e
podem também ser demarcadas sobre terrenos vazios. No primeiro caso, visam
flexibilizar normas e padrões urbanísticos para, através de um plano específico de
urbanização, regularizar o assentamento. No caso de áreas vazias, o objetivo é
aumentar a oferta de terrenos para habitação de interesse social e reduzir seu custo.
Disponível em: Guia para regulamentação e implementação de Zonas Especiais de
Interesse Social - ZEIS. (BRASIL, 2009 p. 55).

O Ministério das Cidades estabeleceu consideravelmente um novo patamar no acesso à moradia qualificada com cidadania e respeito ao uso do solo, e nesse aspecto o nascimento do Sistema e o Fundo Nacional de Habitação de Interesse Social (SNHIS e FNHIS), pela lei federal $\mathrm{n}^{\mathrm{o}} 11.124 / 2005$. Esse marco regulatório permitiu integrar todos os programas destinados à

\footnotetext{
${ }^{8}$ Processos de transformações dos centros urbanos por meio das mudanças dos grupos sociais nos territórios. 
Habitação de Interesse Social de todos os Entes Federados, e tornam as relações institucionais mais fortes no processo de implementação da moradia de interesse social.

Outro avanço importante foi lançamento do PAC - Programa de Aceleração do Crescimento pelo Governo Federal em 2007. O PAC aprofundou as discussões e alargou o processo de acesso à casa própria e melhoraria da qualidade de vida da população de baixa renda, o que garantiu uma redução no déficit habitacional do país; é nesse contexto que mais uma vez emerge a atuação do Governo Federal.

A infraestrutura social e urbana do PAC2 situa-se em eixos como habitação, urbanização de assentamentos precários, prevenção de áreas de risco, saneamento, transporte, recursos hídricos, pavimentação, equipamentos sociais.

De acordo com o último balanço, o programa alcançou, até 30 de junho de 2017, $65,6 \%$ do total previsto para o período $2015-2018$, saindo de $\mathrm{R} \$ 386,6$ bilhões, realizados até dezembro de 2016, para $\mathrm{R} \$ 452,9$ bilhões de investimentos em infraestrutura econômica e social. Desse total, R \$ 123,8 bilhões correspondem aos valores de Financiamento ao Setor Público e do Programa Minha Casa, Minha Vida. (BRASIL, 2015, p. 02).

O PMCMV do Governo Federal lançado em 2009 veio ofertar condições favoráveis para o financiamento de moradias e abrange diversas modalidades de atendimento às famílias de baixa renda nas áreas urbanas. O programa coloca moradia num patamar acelerado, e as operações ocorrem numa parceria entre governo, estados e municípios, com a participação das empresas e entidades sem fins lucrativos no processo de implementação.

O Programa permitiu a construção de UH em grande escala, e que diversas famílias de baixa renda pudessem acessar a política de urbanização, tendo que garantir moradia a uma grande demanda da população brasileira. Sendo um dos maiores programas de assentamento da história do país.

O quadro abaixo aponta dados do Ministério das Cidades referente ao número de unidades entregues desde a sua criação em todo o país, onde apresenta crescimento sistemático no número de famílias assentadas pelo programa, com declínios apenas nos anos de 2015 e 2017 em razão de cortes no orçamento Governo Federal nestes períodos, que acabou por atingir o PAC. 


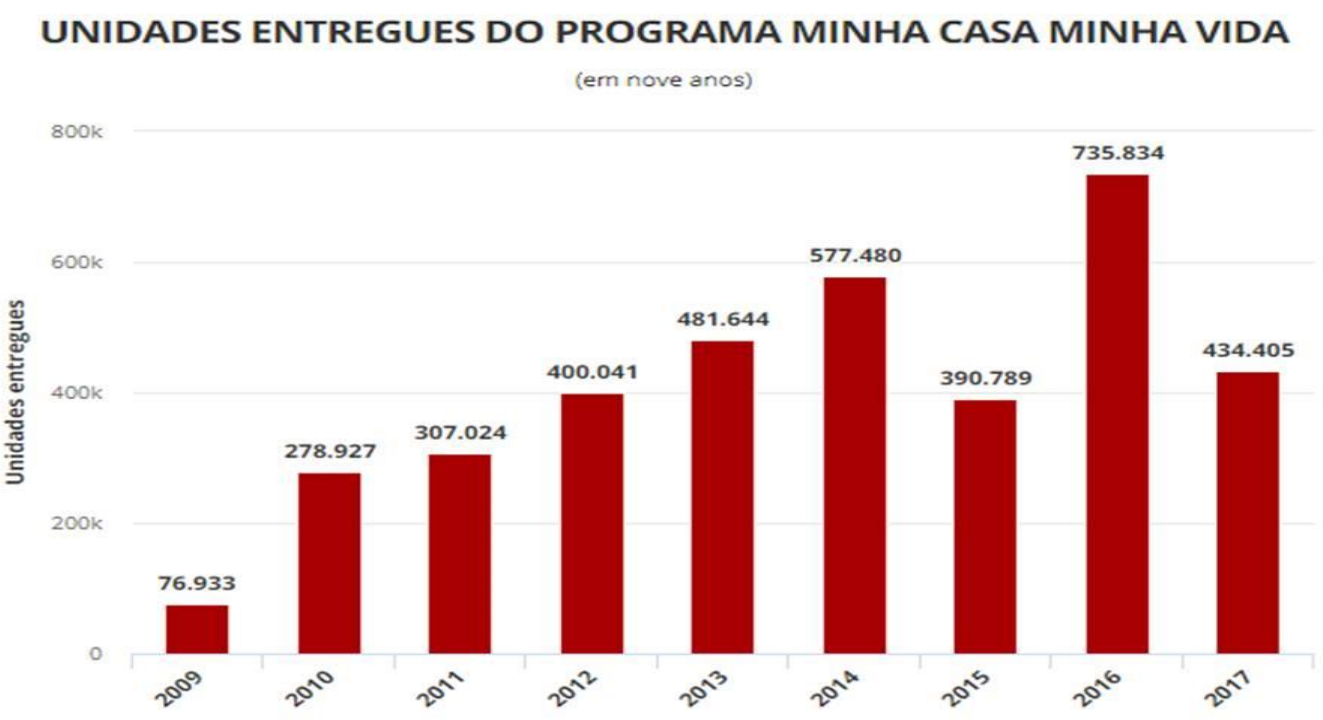

Figura 1 Fonte: Ministério DAS CidAdes $(2017)^{9}$

É uma realidade ainda muito atual no Brasil a questão da falta de infraestrutura urbana, e segundo dados do IBGE, milhões de brasileiros vivem sem as mínimas condições de acesso a serviços básicos dentro das suas casas. Apesar dos avanços obtidos nas últimas décadas na PNH, ainda há muitas metas a serem alcançadas para sanar essa dívida com a população. Os investimentos em infraestrutura ainda não foram suficientes para mudar completamente o panorama das cidades; os números apontam que o cenário de precariedade urbana em muitas cidades ainda é bem presente na atualidade.

A Secretaria de Estado da Infraestrutura - SEINFRA, realizará a $6^{\text {a }}$ Conferência Nacional das Cidades em 2019, conforme decreto 9.076/2017 - publicado do Diário Oficial da União (DOU), e apresentará como eixo condutor a "Função Social da Cidade e da Propriedade: Cidades Inclusivas, Participativas e Socialmente Justas”, por ser o ponto central para o tema do desenvolvimento urbano orientado para a inclusão e a justiça social. A discussão do assunto implica, ainda, no desafio de considerar o interesse social e o individual no espaço urbano em benefício do conjunto da população.

A $4^{\circ}$ Conferência Nacional das Cidades, Com o tema "Cidade para todos e todas com gestão democrática, participativa e controle social", apontou que as cidades brasileiras

\footnotetext{
${ }_{9}^{9}$ Disponível em: https://g1.globo.com/economia/noticia/em-evento-da-caixa-temer-afirma-que-minha-casa-minha-vida-terade-600-ou-700-mil-novas-unidades-em-2018.ghtml. Acessado em 11 de dez. 2017 
abrigavam, há menos de um século, $10 \%$ da população nacional. Atualmente, segundo o último censo/2010/IBGE, passou para $84 \%$.

Segundo Letícia Osório (2003, p. 11) define que, [...] a promoção de políticas públicas pelo poder público e demais atores sociais deve ser realizada mediante a integração das políticas setoriais, tendo como diretriz desta integração a efetivação do direito a cidades sustentáveis. O Ministério da Cidade define que isso tudo é bem mais amplo do que a competência isolada de cada Ente Federado, mais não é maior do que todas as forças da sociedade brasileira que mobilizadas transformam as cidades em ambientes saudáveis, produtivos e sustentáveis. Diante disso, o processo de verificação e de atribuição de valores ao lugar habitado permite o resultado de uma experiência temporal de vivência da habitação a partir dos impactos incididos no território, por consequências dos processos adaptativos.

A portaria 21 criada em 22 de janeiro de 2014, marco regulatório importantíssimo, vem definir o Trabalho de Interesse Social em Programas de Habitação do Governo Federal, define normas e orientações para elaboração, contratação da equipe por processo licitatório e execução interventiva no território. E o maior ganho é que se apresenta como parte exigível da $\mathrm{PNH}$, sendo compreendido como canal entre o poder público e a sociedade. A portaria tem como objetivo principal a promoção da participação social no controle social, a partir da efetivação dos direitos sociais dos beneficiários e a sustentabilidade das intervenções.

[...] este Manual, compreende um conjunto de estratégias, processos e ações, realizado a partir de estudos diagnósticos integrados e participativos do território, compreendendo as dimensões: social, econômica, produtiva, ambiental e políticoinstitucional do território e da população beneficiária, além das características da intervenção, visando promover o exercício da participação e a inserção social dessas famílias, em articulação com as demais políticas públicas, contribuindo para a melhoria da sua qualidade de vida e para a sustentabilidade dos bens, equipamentos e serviços implantados. (BRASIL, 2014, p.05)

Com a missão de tornar o processo de contratação dos executores do Trabalho Social mais transparente, permitindo que a gestão democrática seja estabelecida no processo de escolha da licitante para a execução do trabalho social no território, o Governo Institui a Lei N $^{\circ}$ 8.666, de 21 de junho de 1993. Dentro do processo de Gestão Pública, o processo licitatório compreende a descentralização das ações do Governo, permitindo a terceirização dos serviços na execução do PTS - Projeto Técnico Social.

Em suma, as contratações devem ser pautadas no princípio do direito administrativo, a fim de que atenda todos os requisitos a formalização do acesso à moradia de qualidade, por 
meio de ações articuladas entre os Entes Federados, Organizações da Sociedade Civil e iniciativa privada.

O PTS, objeto de intervenção, pauta-se nos eixos socioeconômico, assistencial, políticoinstitucional e socioeducativo, onde se articulam por um lado, o planejamento, monitoração e avaliação e de outro, a participação e organização da comunidade. Desse modo, a priori, é muito importante que a comunidade tenha acesso as mínimas informações sobre seu novo habitat. As famílias assentadas têm o direito de saber o que vai acontecer com elas, e o repasse de informações não só minimizam os primeiros impactos, como também promove o sentimento de pertencimento e superação de vulnerabilidades identificadas no decorrer dos trabalhos.

[...] as intervenções públicas na área de habitação devem ser acompanhadas por um trabalho social sistemático e que objetive a promoção da inclusão social, do acesso à cidade e aos serviços públicos, e que estimule a participação cidadã. Os processos e ações implementados pela via do trabalho social dão ancoragem e direção a programas de enfrentamento à desigualdade social e sustentabilidade dos programas de Habitação de Interesse Social. (PAZ; TABOADA, 2010, p. 71).

\section{O Trabalho de Interesse Social como um Processo de Intervenção Física e Social, e a Percepção dos Sujeitos Sociais}

Vasconcellos e Garcia (1998) referem que o pensar em desenvolvimento, resultará sempre no crescimento econômico seguido de melhoria na qualidade de vida, ou seja, deve incluir [...] as alterações da composição do produto e a alocação de recursos pelos diferentes setores da economia, de forma a melhorar os indicadores de bem-estar econômico e social (pobreza, desemprego, desigualdade, condições de saúde, alimentação, educação e moradia). De acordo com Celso Furtado, apud Plínio Sampaio Júnior, (1999), o que distingue o processo de desenvolvimento é o projeto social implícito, ou seja, quando o projeto social dá prioridade à efetiva melhoria das condições de vida da maioria da população, o crescimento se metamorfoseia em desenvolvimento; segundo o autor, essa metamorfose não se dá espontaneamente, ela é fruto da realização de um projeto [...].

Para Furtado o desenvolvimento autodeterminado e autossustentado, somente se realiza com a participação do Estado, gerando neste o instrumento responsável pela promoção do desenvolvimento, à medida que é o único, capaz de identificar as demandas sociais. Afirma 
ainda que o Estado deva garantir tanto na alocação de capital, quanto nos investimentos em setores estratégicos da economia, para que assim se identifique as necessidades da população.

Partimos do pressuposto de que o plano urbano deve ser a expressão democrática da sociedade, se se pretende combater a desigualdade. Muito papel foi gasto em torno do conceito de planejamento participativo, sem que a essa produção abundante correspondesse uma prática efetiva de participação social. Evitando encher mais folhas de papel com um tema que parece óbvio, digamos que sem a participação social a implementação do plano se torna inviável e, ele mesmo, inaceitável ao tomar os moradores como objeto e não como sujeitos. (MARICATO, E. 2002, p. 180)

Uma agenda de desenvolvimento efetiva demanda ações voltadas para enfrentar a questão social; no Brasil em particular, o subdesenvolvimento se revelam de maneira multiformes, sendo uma delas a exclusão espacial por vulnerabilidade como já foi amplamente analisado. Neste sentido, pensar um reassentamento com pessoas de baixa renda transcende muito mais do que o simples deslocamento físico, devendo ser considerados aspectos voltados para um desenvolvimento social que supere os recostes historicamente construídos no processo de segregação dos espaços urbanos.

O trabalho social em programas de habitação ganhou visibilidade, obrigatoriedade e regulamentação, e isso é um ganho extraordinário, principalmente frente aos processos adaptativos da população assentada. Evidenciar o grau de sentimento de pertencimento da população beneficiária frente ao novo habitat, isso não apenas como um conceito de nova moradia, mas sim como um universo transformador capaz de quebrar paradigmas a partir dos sujeitos sociais, e é a intervenção que tem o dever de impactar e transformar a realidade de cada morador, e a equipe de trabalho necessita articular a partir de:

1. Mobilização, organização e fortalecimento social - prevê processos de informação, mobilização, organização e capacitação da população beneficiária visando a promover a autonomia e o protagonismo social, bem como o fortalecimento das organizações existentes no território, à constituição e a formalização de novas representações e novos canais de participação e controle social.

2. Acompanhamento e gestão social da intervenção - visa a promover a gestão das ações sociais necessárias para a consecução da intervenção, incluindo o acompanhamento, a negociação ao longo da sua execução, bem como, preparar e acompanhar a comunidade para compreensão desta, de modo a minimizar os aspectos negativos vivenciados pelos beneficiários e evidenciar os ganhos ocasionados ao longo do processo, contribuindo para sua implementação.

3. Educação ambiental e patrimonial - visa a promover mudanças de atitude em relação ao meio ambiente, ao patrimônio e à vida saudável, fortalecendo a percepção crítica da população sobre os aspectos que influenciam sua qualidade de vida, além de refletir sobre os fatores sociais, políticos, culturais e econômicos que determinam 
sua realidade, tornando possível alcançar a sustentabilidade ambiental e social da intervenção.

4. Desenvolvimento socioeconômico - objetiva a articulação de políticas públicas, o apoio e a implementação de iniciativas de geração de trabalho e renda, visando à inclusão produtiva, econômica e social, de forma a promover o incremento da renda familiar e a melhoria da qualidade de vida da população, fomentando condições para um processo de desenvolvimento sócio territorial de médio e longo prazo. (BRASIL, 2014, p.11)

A preparação da equipe frente às ações que serão desenvolvidas é um momento de grande mobilização no trabalho, e é dessa pactuação que depende o grau de conhecimento da população sobre o projeto e o seu engajamento com a proposta de mudanças para o território e para as famílias. O envolvimento, a mobilização e a motivação da nova comunidade em aderir às ações propostas é condição essencial para a continuação e efetividade do trabalho social. São necessários investimentos de comunicação e informação e abordagens de visitas e diálogos, pois o trabalho social incide diretamente nas relações sociais e culturais do grupo social em questão.

Considerando os impactos do trabalho de interesse social pós-ocupação que ocorreu no município de Juazeiro - Bahia, no Residencial Brisa da Serra, Loteamento Parque Residencial, realizados no âmbito do PMCMV, verifica-se 1.500 Unidades Habitacionais sobrepostas e subdividas em blocos compostos de quatro a oito UH com entradas independentes. Todas as UH possuem hidrômetro e medidores de energia elétrica individual com uma sala, uma cozinha compartilhada com a área de serviço, um banheiro, dois quartos e garagem compartilhada. $\mathrm{O}$ residencial dispõe de cinco centros comunitários e cinco quadras poliesportivas, as ruas possuem revestimento asfáltico, saneamento básico, rede de iluminação pública e acesso a transporte público com deslocamento de aproximadamente de 20 a 30 minutos até o centro do município. [...] A cidade deve ser compreendida como forma espacial e lugar de concentração da produção, circulação, edificações, população, consumo de bens e serviços. A cidade, que concentra e difunde o urbano, é um centro de decisão política (RODRIGUES, 2007, p.79).

O Residencial faz parte do Loteamento Parque Residencial no bairro João Paulo II, sendo seus moradores beneficiados pela oferta de serviços do poder público dos entornos, tais como: Unidade Básica de Saúde, Restaurante Popular, CRAS - Centro de Referência de Assistência Social, Serviço de Segurança Pública (policiamento) e oferta de educação em diferentes níveis de escolaridade; conta também com serviços do segundo e terceiro setor: correspondente bancário, comércio varejista diversificado (supermercados, vestuário, calçados, farmácias, perfumarias, móveis, padarias, etc.), centros religiosos diversificados, Associação 
de Moradores que oferece a população biblioteca comunitária, centro digital e sistema de som comunitário. Em suma, a comunidade está inserida em localidade com infraestrutura adequada em seus entornos, porém verifica-se que os moradores ainda não acessam tais serviços dentro do próprio residencial, sendo esta uma comunidade que comporta mais seis mil habitantes.

Moradia digna é aquela localizada em terra urbanizada, com acesso a todos os serviços públicos essenciais por parte da população que deve estar abrangida em programas geradores de trabalho e renda. Moradia é um direito humano, afirma o Tratado dos Direitos Econômicos e Sociais da Organização das Nações Unidas (ONU), ratificado pelo Brasil em 1992, e como tal deve ser reconhecido, protegido e efetivado através de políticas públicas específicas (PROJETO MORADIA, 2000, p.12).

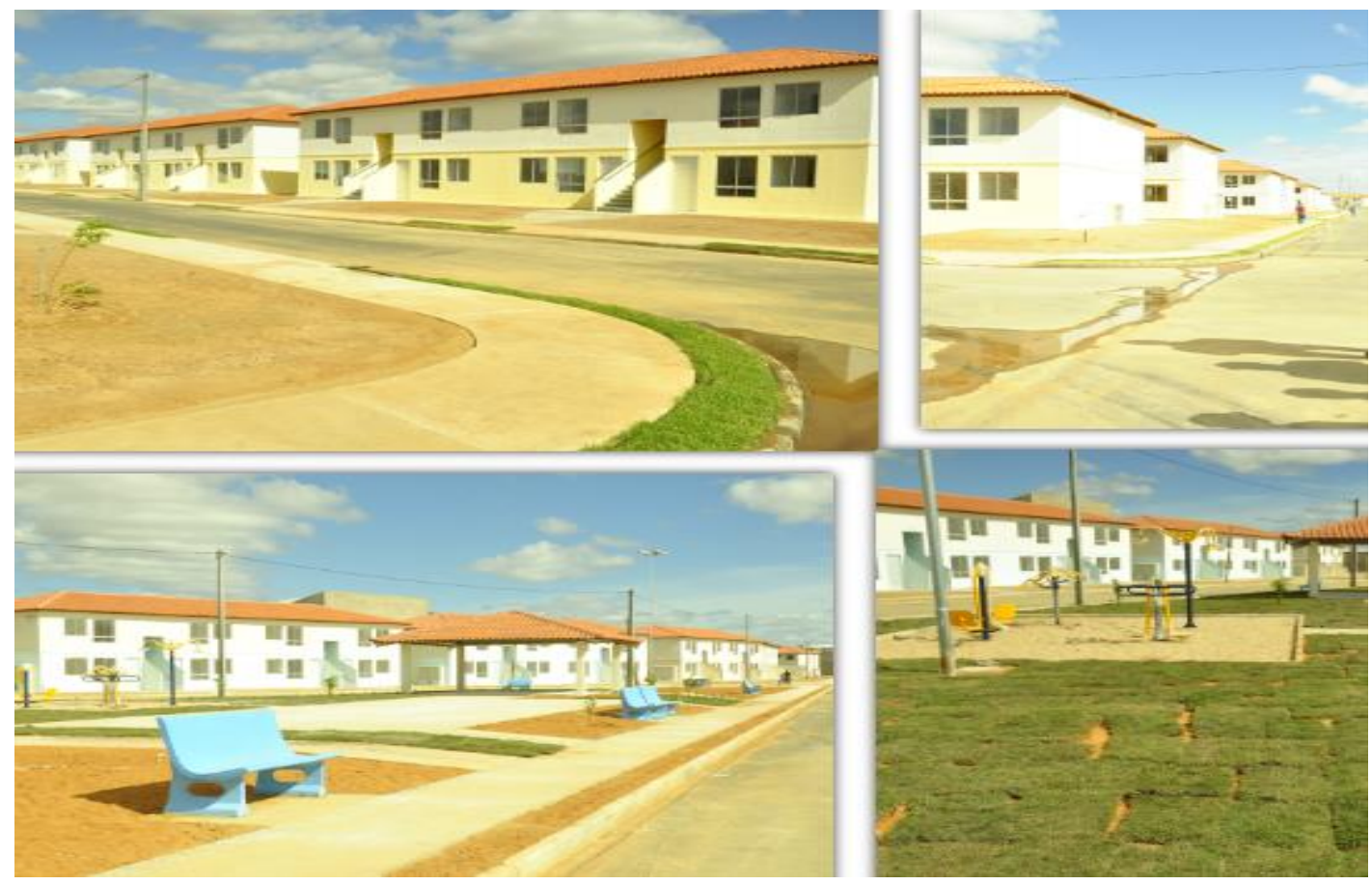

Figura 2 Residencial Brisa da Serra - Juazeiro (BA)

Fonte: http://geraldojose.com.br/index.php?sessao=noticia\&cod_noticia=49584. Acesso em 22.03.18

O trabalho realizado no residencial contou com uma equipe multiprofissional contratada por uma empresa da iniciativa privada por processo licitatório da prefeitura do município. $\mathrm{O}$ residencial foi inaugurado em outubro de 2014 e a intervenção teve seu inicio em setembro de 2016, portanto o projeto foi executado após dois anos das assinaturas dos contratos, vistorias e entrega das chaves aos moradores, e foi desenvolvido durante 15 meses. O espaço de tempo de dois anos para o inicio da intervenção no residencial provocou nas famílias assentadas 
adequações individualizadas ao novo habitat, prescindindo o principio de coletividade, pertencimento e responsabilidade social essencial à implantação da gestão condominial.

Este é um dos grandes desafios para as equipes sociais, o acompanhamento sistemático e ininterrupto da nova comunidade nas etapas que antecedem a obra, durante a obra e pós-obra, sendo que os vínculos só devem ser quebrados ao final do tempo determinado para ocorrer à intervenção, a partir de então a autonomia adquirida por meio das ações do projeto devem ser monitoradas e acompanhadas por outros setores do poder público e da sociedade civil organizada.

É importante ressaltar que a quebra de vínculos entre a equipe social e famílias antes e pós-ocupação acarretou descrédito nas ações do poder público, e consequente desmotivação da comunidade na adesão às atividades do projeto. Como forma de aproximar a comunidade, a equipe social a priori, percebeu a necessidade da implantação de uma sede - Plantão Social em um dos centros comunitários, que permitiu a mobilização dos moradores na adesão às ações interventivas do projeto.

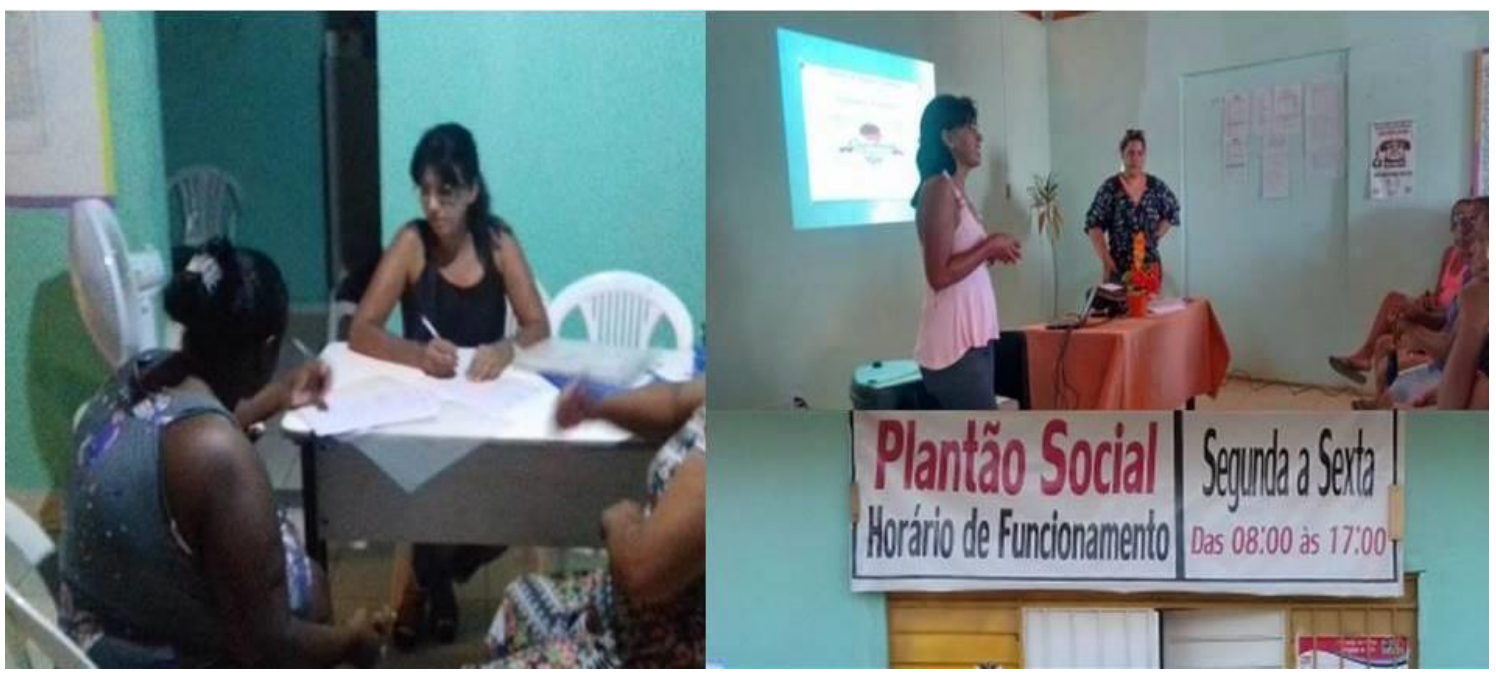

Figura 3 - Atendimento aos moradores e palestra realizada na sede Plantão Social.

As articulações com os demais atores que integram a rede de parcerias (público, privada e $\mathrm{ONGs}^{10}$ ), foram imprescindíveis para a implementação das atividades programadas, que

${ }^{10}$ Organizações Não Governamentais 
viriam a evidenciar a habitabilidade dos espaços, e que tiveram foco em ações socioeducativas ambientais, de saúde, profissionalização, geração de emprego e renda, reuniões e palestras informativas sobre a gestão condominial voltada para a organização comunitária, responsabilidade social e sustentabilidade do ambiente, entre outros temas adaptados as necessidades da comunidade, sempre em conformidade com as reprogramações do projeto. Alguns atores importantes que estiveram envolvidos no nivelamento interventivo: CRAS, CREAS $^{11}$, Conselho Tutelar e demais Concelhos de Direito, OAB ${ }^{12}$, SEBRAE $^{13}$, Delegacia Especializada de Mulheres, Secretária Municipal de Saúde, Secretária Municipal de Meio Ambiente, Associação de Moradores do bairro João Paulo II.

Teixeira (2001, p.30), refere-se à participação cidadã como um "processo complexo e contraditório entre sociedade civil, Estado e Mercado, em que os papéis se redefinem pelo fortalecimento dessa sociedade civil, mediante a atuação organizada de indivíduos, grupos e associações".

No processo interventivo evidenciou-se também a necessidade de rescindir conceitos de que moradia é a simples aquisição das UH. A relação do morador com habitar vai além da conjuntura arquitetônica do imóvel, pois envolve o sentimento de pertencimento a partir das respostas que o ambiente lhe agrega [...] Um resultado efetivo, uma resposta emocional ou uma consequência de caráter positivo que provém da comparação entre o ambiente residencial e a própria situação do sujeito. Todo ele considerando um processo cíclico e dinâmico, em que a pessoa vai se adaptando a cada situação residencial concreta. (AMÉRIGO, 1995, p.55 apud VILLA, 2013).

Reis Cabrita (1995) conceitua moradia a partir de influências do campo filosófico, psicológico e fisiológico, o autor refere que nelas são reproduzidas à satisfação de aspirações e necessidades que vem a determinar subjetivamente o bem-estar de uma pessoa. Subsídios estes que permitam configurar a habitabilidade do ambiente, proporcionando não somente o abrigo, mas qualidade de vida. Tais percepções transformam uma população excluída em sujeitos sociais, conscientes de seu papel e da função da cidade, com capacidade de exercer a sua cidadania e desenvolver ambientes sustentáveis.

\footnotetext{
${ }^{11}$ Centro de Referência Especializado de Assistência Social

${ }^{12}$ Organização dos Advogados do Brasil

${ }^{13}$ Serviço de Apoio às Micro e Pequenas Empresas 
Nesse projeto a equipe pode evidenciar aspectos que envolvem as contradições da política de habitação, visto que nem todos os residenciais projetados para o PMCMV têm boa localização e possuem infraestrutura como a comunidade Brisa da Serra, e que mesmo diante destes aspectos positivos, apresentam também negatividades, como: espaço limitado das UH, que de alguma forma [...] o sentir-se abrigado, seguro, o alimentar, o dormir, o higienizar-se, competem com os espaços, com os mobiliários e equipamentos (LEITE, 2006 apud Villa (2015, p 13)).

Rifrano Leite (2006), apud Villa (2015, p 15) descreve ainda que existam alguns pontos críticos na habitação de interesse social que merecem ser apontados, pois, [...] o problema das HIS não se limita à ineficiência do "modelo de morar mínimo", visto que a tendência à periferização dos conjuntos habitacionais agrava a situação [...], que de certo modo intensifica a favelização dos conjuntos habitacionais e agrava uma situação recorrente. Dentro dessa conjuntura, veem-se empreendimentos projetados por empresas da iniciativa privada, que para minimizar os gastos trabalham com recursos reduzidos. Observa-se também, que para redução de custos ou tempo de execução das obras, tais empresas aumentam a escala de produção, que acarreta consequentemente uma redução da qualidade das UHs. Tais estratégias reforçam o processo de periferização, em contra partida da necessidade de se trabalhar com terrenos bem maiores, sendo que é mais remota a possibilidade de encontrar áreas de tamanho e valores relativos aos ambicionados pelas empresas nas regiões centrais das cidades. O Estatuto da Cidade em seu Art. $2^{\mathrm{a}}$, parágrafo XV, especifica: simplificação da legislação de parcelamento, uso e ocupação do solo e das normas edilícias, com vistas a permitir a redução dos custos e o aumento da oferta dos lotes e unidades habitacionais.

A avaliação pós-ocupação dos programas de habitações de interesse social é parte importante na efetivação da política de habitação e confere uma analise das perspectivas em torno da execução as ações.

Ao analisar a intervenção do Residencial Brisa da Serra, os profissionais constataram que as articulações para implementação das ações voltadas para a geração de emprego e renda foram as que mais atraíram os moradores, o que evidenciou um índice de desemprego considerável no residencial, e assim a necessidade da inserção no mundo do trabalho ou mesmo da profissionalização para o desenvolvimento de prestação de serviços autônomos. A busca por atendimento no plantão social se deram de forma mais intensas apenas nos três primeiros meses, sendo uma procura maior para relatos de conflitos comunitários, nos meses subsequentes os 
atendimentos foram reduzidos para esclarecimentos e informações sobre as atividades do projeto (palestras, cursos, reuniões, encaminhamentos para a rede sócio assistencial, serviços da Caixa Econômica Federal - instituição financiadora das UH, ou agendamento para visita técnica da construtora responsável pela edificação do residencial).

Um fator que pode ter provocado a não adesão nas atividades por parte de alguns comunitários estava relacionada a questões laborais, muita se ausentavam de suas UH durante o período diurno, só retornando a noite. Durante as visitas domiciliares noturnas evidenciou-se certa fadiga do labor, que os limitava no engajamento das ações noturnas.

As questões ambientais e desenvolvimento sustentável estiveram presentes diariamente nas ações do PTS. Abordar a questão de educação sanitária e ambiental por meio de visitas in loco permitiu ao Plantão Social tratar à mudança de comportamento por meio da sensibilização e do desenvolvimento do senso crítico de forma a incorporar atitudes ambientalmente sustentáveis. A priori os técnicos elaboraram o roteiro de visitação a partir das demandas que necessitavam de intervenção imediata, o que permitiu nas atividades coletivas uma abordagem horizontal.

Com o termino do projeto e com uma avalição relativamente boa em relação à participação uma significativa da comunidade, a equipe destacou como principais resultados: o empoderamento feminino, pela visível participação de mulheres referência familiar; possibilidade de autonomia financeira, emprego e renda frente às ações do SEBRAE e outros atores financeiros importantes, como também a oferta de cursos profissionalizantes com certificação; a implantação da gestão condominial por meio de eleição da Equipe Gestora (síndico, subsíndico); resolução razoável de parte das questões técnicas de edificação por meio da presença da construtora responsável pela construção do residencial; o evidente sentimento de pertencimento das famílias em relação ao novo habitat; a visível ampliação do conceito de moradia pelos moradores participantes a partir do entendimento da função da cidade; a adesão dos moradores as ações de desenvolvimento ambiental e de sustentabilidade; e como norteador principal da avaliação pós-projeto evidenciou-se a satisfação dos moradores que aderiram as atividades.

A sustentabilidade das ações desenvolvidas e o olhar da comunidade será sempre um contraponto à avaliação objetiva dos eixos moradia e inclusão urbana e social. A equipe chegou à concepção de que a ênfase da avaliação de pós-ocupação é a satisfação do morador mediante 
a ressignificação de seu conceito de habitabilidade, por meio de moradia de qualidade com acesso a bens, infraestrutura, serviços e sustentabilidade do ambiente.

\section{Considerações Finais}

A população brasileira cresceu, porém seguida da má distribuição de riquezas e de um quadro de desigualdades que exclui uma população vulnerável por um sistema injusto, e dentro do processo de exclusão espacial introduz-se providencialmente a política de habitação para corrigir esse panorama político, que por meio de uma reforma urbana busca transformar as cidades em ambientes mais equitativos, através de seus sujeitos sociais conscientes de seus direitos e deveres.

O controle social na política de habitação situa-se nos eixos que envolvem inserção urbana, inclusão social, melhoria da qualidade de vida, sustentabilidade ambiental e satisfação dos moradores. Estes indicadores é que transformam as cidades em locais democráticos e com mais justiça social. O trabalho social em habitação de interesse social é parte importante no processo de urbanização e permite detectar os resultados e impactos, e ajustar as ações de acordo com a realidade de cada território.

Entender a função da cidade não compete apenas aos Entes Federados, e sim a todos os cidadãos. Moradia deve ser entendida para além da conquista da UH, pois a aquisição da casa não encerra um ciclo que sabemos ter batalhas bem maiores. Em meio a tantas considerações e contradições sobre o processo de inclusão espacial com famílias de baixa renda, é notória a importância do trabalho de interesse social em todo o processo de assentamento; pois é essa metodologia técnica operacional que põem em relevo todo o trabalho, que tem o dever de ser fundamentado em relações democráticas. Toda essa estratégia participativa deve prevê ações de modo a possibilitar a autonomia e emancipação dos sujeitos, permitindo que estes realizem leituras críticas do processo de assentamento.

Os Programas de Habitação tem em suas prerrogativas assegurar o acesso à cidade infraestruturada por meio das intervenções urbanas, e apesar de garantir a UH para a população de baixa renda, não tem garantido a qualidade das UH e inserção adequada nos espaços urbanos. Quando o direito a moradia é mercantilizando, a relação entre moradia e bem estar dos beneficiários torna-se distinta, permitindo assim, uma discursão acerca do "morar mínimo" e 
da insuficiência de moradia digna. A lógica da produção de UH em grande escala poderia ser repensada, tornando viável a construção de conjuntos habitacionais com um número reduzido de imóveis, mas que garantissem espaços adequados e com capacidade de contemplar o bem estar dos seus moradores.

Ao fim desse trabalho, conclui-se que os sujeitos sociais é que transformam as cidades em locais com habitabilidade a partir do seu entendimento do que vem a ser moradia. O controle social necessita sempre passar pelo crivo da população para que as políticas públicas tenham real efetividade. A comunidade do Residencial Brisa da Serra aderiu às ações do projeto à medida que eram confrontados em suas ideias e conceitos acerca de moradia, passando a tratar o tema como uma necessidade de se garantir que o residencial terá os acessos necessários, dessa forma, fazendo com que a cidade cumpra o seu papel por meio das políticas de desenvolvimento sustentáveis.

A comunidade Brisa da Serra representa apenas uma pequena parcela de uma população que anseia por inclusão nos processos de desenvolvimento da sociedade madura, porém para que isso ocorra é essencial entender a cidade real como ela é, para assim introduzir a cidade legal. E que a garantia de direitos jamais se confunda com oportunidades, pois direito é algo exigível. $\mathrm{O}$ trabalho de interesse social com famílias de baixa renda não é tarefa fácil, mas às dificuldades acabam se tornando campo fértil para ressignificação de conceitos e formação de pensamento crítico em relação a sua própria condição. A equipe chegou à conclusão de que os moradores engajados no projeto entenderam a função da cidade, como também a função dos mesmos enquanto sujeitos sociais, com total capacidade de transformar a sua realidade por meio de ações conscientes e organização coletiva sustentável; nesse sentido a participação da comunidade se tornou um eixo importante de avaliação na construção efetiva dos Programas de Assentamento Urbanos.

\section{Referências}

ARANTES, Otília; VAINER, Carlos; MARICATO, Ermínia. A cidade do pensamento único: desmanchando consensos. $2^{\mathrm{a}}$ ed. 2002. p 1-192.

BRASIL. Constituição Federativa do Brasil 1988. Brasília, 1998. 
Ministério das Cidades Estatuto da Cidade. Brasília, 2001.

Ministério das Cidades. Programa Minha Casa Minha Vida: Novo Patamar da Habitação Social Brasileira. Brasília.

Ministério das cidades. PAC 5 Balanço 2015 - 2018. Brasília, 2017.

Ministério das Cidades Portaria no 21. Brasília, 2014.

Secretaria Nacional de Habitação do Ministério das Cidades Pesquisa de Satisfação dos Beneficiários do Programa Minha Casa Minha Vida. Câmara, Centro de Documentação e Informação Coordenação. Edições Câmara - Brasília 2015.

IBGE. Brasil em Números, Rio de Janeiro, v. 21, p. 1-392, 2013.

Conjunto CFESS CRESS Questão Urbana. Atuação de assistentes sociais na Política Urbana - subsídios para reflexão. Brasília, 2016.

Guia para regulamentação e implementação de Zonas Especiais de Interesse Social - ZEIS em Vazios Urbanos Brasília. Ministério das Cidades Primeira impressão: Dezembro de 200955 p.

Ministério do Meio Ambiente. Sustentabilidade urbana: impactos do desenvolvimento econômico e suas consequências sobre o processo de urbanização em países emergentes. Textos para as discussões da Rio+20: v. 3 habitação social e sustentabilidade/Nunes, Tarcísio..., [et al]. Brasília, 2015.

O Estatuto da Cidade: comentado = The City Statute of Brazil: a commentary /organizadores Celso Santos Carvalho, Anaclaudia Rossbach. - São Paulo: Ministério das Cidades : Aliança das Cidades, 2010. 120 p.

Balanço PAC 2015 - 2018. Ministério do Planejamento. Disponível em: http://www.pac.gov.br/pub/up/relatorio/c459e7bfc39c3f57794d61e42e24851b.pdf

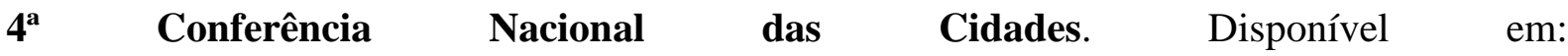
www.ipea.gov.br/.../conferencias/Cidades_IV/texto_base_4_conferencia_cidades.pdf. Acessado em: 15 de set. 2017.

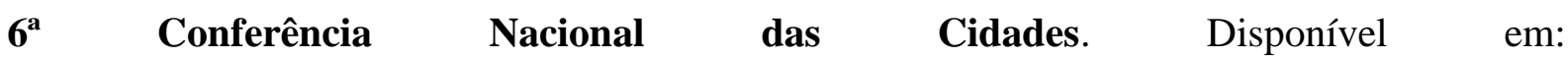
http://app.cidades.gov.br/6conferencia/images/arquivos/texto_refer\%C3\%AAncia_etapa_mun icipal.pdf. Acessado em: 15 de set. 2017.

BONDUKI, N. G. Origens da Habitação Social no Brasil. Analise Social, 711-732. (1994).

BONDUKI, Nabil. A Reforma Urbana no Processo de Participação Popular na Constituinte. In: Constituição 20 Anos: Estado, Democracia e Participação Popular: caderno de textos. Brasília: Edições Câmara, 2009. 
CABRITA, António Manoel Reis. O Homem e a Casa: Definição Individual e Social da Qualidade da Habitação. Laboratório Nacional de Engenharia Civil. Lisboa PT 1995. 181 p. ISBN 972-49-1631-6.

CAFRUNE, Marcelo Eibs $\mathbf{O}$ direito à cidade no Brasil: construção teórica, reivindicação e exercício de direitos. RIDH| Bauru, v. 4, n. 1, p. 185-206. 2016.

CÂMARA, EDITORA. Centro de Documentação e Informação Coordenação Edições Câmara. Legislação sobre licitações e contratos administrativos. 3ª edição - Brasília 2014.

CENSO IBGE 2010, Disponível em: http://www.ibge.gov.br. Acessado em: 20 de nov. 2017.

COVEY, S. M. R. O poder da confiança: o elemento que faz toda a diferença. Rio de Janeiro: Elsevier, 2008.

DAVIS, Mark. Planeta favela. São Paulo: Boitempo Editorial, 2006.

DUARTE, Rosália. Pesquisa Qualitativa: Reflexões Sobre o Trabalho de Campo. Cadernos de Pesquisa, 2002.

GOMES e PELEGRINO. Política de Habitação Popular e Trabalho Social. Editora: DP\&A, 2005 .

JÚNIOR, Nelson Saule e UZZO, Karina. A Trajetória da Reforma Urbana no Brasil.. Ford Foundation. Experiências do Marco Legal, p. 259- 269. São Paulo, 2009.

LEITE, Luiz Carlos Rifrano. Avaliação de Projetos Habitacionais: Determinando a Funcionalidade da Moradia Social. São Paulo. 2006. 161 p.

MARICATO, Ermínia. O Ministério das Cidades e a Política Nacional de Desenvolvimento Urbano. Políticas Sociais - acompanhamento e análise/12/fev. 2006.

MARICATO, Ermínia. Urbanismo na Periferia do Mundo Globalizado: Metrópoles Brasileiras. São Paulo em Perspectiva, 2000.

MATOS, Ralfo; BAENINGER, Rosana. Migração e Urbanização no Brasil: Processos de Concentração e Desconcentração Espacial e o Debate Recente. Cadernos do Leste, 2008.

OSÓRIO, Leticia. Direito à Moradia no Brasil. - Fórum Nacional de Reforma Urbana, 2003.

PAZ e TABOADA. Trabalho Social em Programas e Projetos de Habitação de Interesse Social (1 $1^{\mathrm{a}}$ edição, Vol. Primeira i). Brasília, 2010.

RODRIGUES, A. M. Conceito e definição de cidades. In: Queiroz R. L.C. E Santos Jr., O. A. (Orgs). As Metrópoles E A Questão Social Brasileira. Rio de Janeiro: REVAN/FASE, 2007. 
SAMPAIO JR, Plínio de Arruda. Desenvolvimentismo e Neodesenvolvimentismo: tragédia e farsa. Serv. Soc. Soc., São Paulo, n. 112, p. 672-688, out./dez. 2012.

SAMPAIO JÚNIOR, Plínio de Arruda. Entre a Nação e a Barbárie. Rio de Janeiro: Vozes, 1999. 254 p. Cap. 5: Progresso Técnico e desenvolvimento em Celso Furtado, p. 169-200.

SAULE JR., Nélson; OSÓRIO, Letícia. Direito à Moradia no Brasil. Relatório Nacional. Plataforma Brasileira dos DHESC. Voluntários das Nações Unidas - UNDP. 2002, p.11.

TEIXEIRA, Elenaldo. O local e o global: limites e desafios da participação cidadã. São Paulo: Cortez, 2001.

VASCONCELOS, Marco Antonio; GARCIA, Manuel Enriquez. Fundamentos de economia. São Paulo: Saraiva, 1998.

VILLA, Simone Barbosa; Ornstein, Sheila Walbe. Qualidade Ambiental na Habitação, avaliação pós ocupação. São Paulo: Oficina de Textos, 2013)

VILLA, Simone Barbosa; PEREIRA, Rita de Cássia Saramago; GARCIA Lucianne Casasanta. Avaliação Pós-Ocupação No Programa Minha Casa Minha Vida Uma Experiência Metodológica. (Vol. 1 ${ }^{\text {a }}$ edição). Uberlândia UFE/PROEX. 2015.

WOLKMER, Antônio Carlos. Pluralismo jurídico, direitos humanos e interculturalidade. Revista Sequiência, no 53, p. 113-128, dez. 2006.

XAVIER, André..., [et al].Trabalho Social em Programas de Habitação de Interesse Social. $2^{a}$ edição, 2014.

Como citar este artigo (Formato ABNT):

BARRETO, Sônia Regina T.; KURSANCEW, Fernando Augusto. Habitação de Interesse Social: Cidades transformadas pela inclusão dos sujeitos sociais e a experiência no semiárido. Id on Line Revista Multidisciplinar e de Psicologia, 2018, vol.12, n.40, p. 1013-1036. ISSN: 19811179.

Recebido: 21.05.2018

Aceito: 28.05.2018 